\title{
Synthesis of thermo- and photoresponsive polysilsesquioxane containing tetraethylene glycol chains and an azobenzene group
}

\author{
Bagus Alimada, Shin-ichi Yamamoto and Osamu Moriya \\ Polymer Journal (2014) 46, 243-249; doi:10.1038/pj.2013.92; published online 25 December 2013
}

Keywords: azobenzene; photochemical isomerization; polysilsesquioxane; tetraethylene glycol; thermoresponsive hybrid

\section{INTRODUCTION}

Polysilsesquioxane (PSQ) is known as a new member of the silicone family, which has a main chain that usually consists of T-type siloxane units. ${ }^{1-3}$ Various PSQs have been functionalized to be useful hybrid materials by modification of their organic substituents. ${ }^{4-7}$ Because of the introduced organic group based on the inorganic polysiloxane backbone, the modified PSQ is expected to exhibit properties such as durability for heat and weatherability based on the inorganic polysiloxane backbone. Recently, the reversible thermoresponsive phase separation of synthetic polymers in aqueous solutions have attracted much attention. ${ }^{8-10}$ PSQs with the thermoresponsive property are expected to be practical hybrids, because such functionalized PSQs seem applicable to absorbents, biosensors, microencapsulation materials, drug delivery reagents and adhesives. Because of the interests in these expanded usages, we have continuously investigated the thermoresponsive PSQs by introducing polymeric and low-molecular-weight organic substituents.

Our studies have showed that the simple oxyethylene substituents with hydrophobic alkyl groups, such as methyl and ethyl groups, are effective in providing the thermoresponsive property to PSQs. ${ }^{11-13}$ Furthermore, in the previous works, the presence of polymeric ethylene glycols is reported to enable sensitive phase separation, easy tuning of the lower critical solution temperature (LCST) and multifunctionalization. ${ }^{14,15}$ In addition, the polymeric oxyethylene structure possesses advantages, such as biocompatibility, amphiphilicity and high flexibility. ${ }^{16-23}$ Therefore, the oxyethylene structures have been introduced into various polymers to lead to the stimuli-responsive properties in an aqueous solution. ${ }^{24-26}$ These studies suggest that the combination of the polysiloxane backbone with ethylene glycol chains provides a new multistimuli-responsive hybrid material that can be employed in various situations with environmental compatibility. This promising finding has led us to investigate the new thermoresponsive PSQs that contain the ethylene glycol chains.
In our preliminary experiments, several oligo(ethylene glycol) chains were found to provide an adequate reversible thermoresponsive aggregation behavior in conjunction with the hydrophobic components. In this work, the PSQ derivatives containing tetraethylene glycol chains with a hydrophobic 4-phenylazobenzene group were newly prepared, and their reversible aggregation behaviors in aqueous solution were evaluated. The hydrophobic component is chosen to obtain fundamental information on the multistimuli responsiveness, which is caused by a reversible photo-induced geometrical isomerization of the structure. Such dual-responsiveness to both heat and light is induced by isomerization of the azobenzene structure and, was reported previously by several groups, including us, as a useful property. ${ }^{27-36}$

For the synthesis of the new of PSQ derivatives, the silane-coupling agents were prepared according to our previous procedure in which (3-isocyanatopropyl)triethoxysilane $\left(\mathrm{C}_{10} \mathrm{H}_{21} \mathrm{NO}_{4} \mathrm{Si}\right.$, ICTES) was employed as a starting compound. ${ }^{12,13}$ Namely, tetraethylene glycol chains were introduced into the silane-coupling agents via a urethane bond. By using the obtained silane-coupling agents as building blocks, various PSQ derivatives containing tetraethylene glycol chains were readily prepared.

\section{EXPERIMENTAL PROCEDURE}

\section{General}

The ${ }^{1} \mathrm{H}$ nuclear magnetic resonance (NMR) and ${ }^{13} \mathrm{C}$ NMR spectra were obtained of samples in $\mathrm{CDCl}_{3}$ using a JEOL AL-300 spectrometer (JEOL Co, Tokyo, Japan). The ${ }^{29} \mathrm{Si}$ NMR measurements were carried out with samples and tetramethylsilane as a standard in $\mathrm{CDCl}_{3}$ solution on a Bruker AVANCE500 spectrometer (Bruker Co, Karlsruhe, Germany) operating at 99.4 MHz. An NMR sample tube made of glass $(5 \mathrm{~mm} \phi)$ was used for the measurements. Infrared (IR) spectra were recorded using a JASCO FT/IR 230 (Jasco Co, Tokyo, Hachioji, Japan). Gel permeation chromatographic analysis was carried out to estimate the number-average-molecular weight $\left(M_{\mathrm{n}}\right)$ and polydispersity $\left(M_{\mathrm{w}} / M_{\mathrm{n}}\right)$ using a Shimadzu LC-10VP chromatograph 
(Shimadzu Co, Kyoto, Japan) equipped with an evaporative light scattering detector. Three columns, such as the Shim-pack gel permeation chromatographic-80MD, $-804 \mathrm{D}$ and $-802 \mathrm{D}$, were connected in series and $\mathrm{N}, \mathrm{N}$ dimethylformamide $\left(\mathrm{C}_{3} \mathrm{H}_{7} \mathrm{~N}_{2} \mathrm{O}\right)$ was used as the eluent. Calibration was performed using poly(methyl methacrylate) standards. The Tetrahydrofuran $\left(\mathrm{C}_{4} \mathrm{H}_{8} \mathrm{O}\right)$ used for the reactions was distilled from sodium benzophenone ketyl before use. Ethyl acetate $\left(\mathrm{C}_{4} \mathrm{H}_{8} \mathrm{O}_{2}\right)$, nhexane $\left(\mathrm{C}_{6} \mathrm{H}_{14}\right)$, ICTES, tetraethylene glycol $\left(\mathrm{C}_{8} \mathrm{H}_{18} \mathrm{O}_{5}\right)$, tetraethylene glycol monomethyl ether $\left(\mathrm{C}_{9} \mathrm{H}_{20} \mathrm{O}_{5}\right)$, 4hydroxyphenylazobenzene $\left(\mathrm{C}_{12} \mathrm{H}_{10} \mathrm{~N}_{2} \mathrm{O}\right)$ and triethylamine $\left(\mathrm{C}_{6} \mathrm{H}_{15} \mathrm{~N}, \mathrm{Et}_{3} \mathrm{~N}\right)$ were used as supplied from commercial sources.

\section{Synthesis of a silane-coupling agent containing tetraethylene glycol} chain

Typical procedure. ICTES $(5.00 \mathrm{~g}, 20.21 \mathrm{mmol})$ was added slowly to a solution of tetraethylene glycol monomethyl ether $\left(4.21 \mathrm{~g}, 20.21 \mathrm{mmol}\right.$ ) and $\mathrm{Et}_{3} \mathrm{~N}$ $(0.10 \mathrm{~g}, 0.99 \mathrm{mmol})$ in Tetrahydrofuran $(5.0 \mathrm{ml})$, at ambient temperature. After stirring for $24 \mathrm{~h}$ at $50^{\circ} \mathrm{C}$, the resulting solution was evaporated under reduced pressure to concentrate the solution. The residue was chromatographed on silica gel (ethyl acetate- ${ }^{\mathrm{n}}$ hexane) to obtain the silane-coupling agent (TeMTES as an oil (7.86 g, 85\% yield): IR (neat) 3340, 2970, 2930, 2880, 1720, 1530 and $1100 \mathrm{~cm}^{-1} ;{ }^{1} \mathrm{H}$ NMR $\left(\mathrm{CDCl}_{3}\right) \delta 0.55\left(\mathrm{t}, 2 \mathrm{H}, J=8.1 \mathrm{~Hz}, \mathrm{Si}_{-} \mathrm{CH}_{2}-\right), 1.15(\mathrm{t}, 9 \mathrm{H}$, $\left.J=6.9 \mathrm{~Hz}, \mathrm{Si}-\mathrm{O}-\mathrm{CH}_{2}-\mathrm{CH}_{3}\right), 1.54\left(\mathrm{~m}, 2 \mathrm{H}, \mathrm{Si}-\mathrm{CH}_{2}-\mathrm{CH}_{2}-\right), 3 . \overline{9}\left(\mathrm{~m}, 2 \mathrm{H},-\mathrm{CH}_{2}-\right.$ $\mathrm{NH}-), 3.30\left(\mathrm{~s}, 3 \mathrm{H},-\mathrm{O}-\overline{\mathrm{C}} \mathrm{H}_{3}\right), 3.59\left(\mathrm{~m}, 14 \mathrm{H},-\mathrm{O}-\mathrm{CH}_{2}-\mathrm{CH}_{2}-\mathrm{O}-\right), 3.78(\mathrm{~m}, \overline{8} \mathrm{H}$, $\left.\mathrm{Si}-\mathrm{O}-\mathrm{CH}_{2}-\mathrm{CH}_{3}\right), 4.14\left(\mathrm{t}, \overline{2 \mathrm{H}}, J=4.5 \mathrm{~Hz},-(\mathrm{C}=\mathrm{O})-\overline{\mathrm{O}}-\mathrm{CH}_{2}^{-}\right)$and $5.31(\mathrm{br}, 1 \mathrm{H},-$ $\mathrm{NH}-) ;{ }^{\overline{13}} \mathrm{C}$ NMR $\left(\mathrm{CDCl}_{3}\right) \delta 7.0\left(\mathrm{Si}-\mathrm{CH}_{2}-\right), 17.6\left(\mathrm{Si}-\overline{\mathrm{O}}-\mathrm{CH}_{2}-\mathrm{CH}_{3}\right), 22.6(\mathrm{Si}-$ $\left.\mathrm{CH}_{2}-\mathrm{CH}_{2}-\right), 42.8\left(-\mathrm{CH}_{2}-\mathrm{NH}-\right), 57.7\left(\overline{\mathrm{Si}}-\mathrm{O}-\mathrm{CH}_{2}-\mathrm{CH}_{3}\right), 58.2\left(-\overline{\mathrm{O}}-\mathrm{CH}_{3}\right), 63.0$ ($\left.(\mathrm{C}=\overline{\mathrm{O}})-\mathrm{O}-\mathrm{CH}_{2}-\right), \overline{69} .0\left(-(\mathrm{C}=\mathrm{O})-\mathrm{O}-\mathrm{CH}_{2}-\overline{\mathrm{C}} \mathrm{H}_{2}-\mathrm{O}-\right), 69.9\left(-\mathrm{O}-\mathrm{CH}_{2}-\mathrm{CH}_{2}-\mathrm{O}-\right)$, $71.3\left(-\mathrm{CH}_{2}-\mathrm{O}-\mathrm{CH}_{3}\right)$ and $155.9(-(\mathrm{C}=\mathrm{O})-\overline{\mathrm{O}}-)$.

Analogously, the use of 0.5 equiv. of ICTES to the tetraethylene glycol produced the silane-coupling agent (TeTES) containing the hydroxyl group at one end of the tetraethylene glycol chain as a wax in $82 \%$ yield.

\section{Synthesis of a silane-coupling agent containing an azobenzene group (AzTES)}

Using the similar procedure to the preparation of TeMTES, from the reaction of ICTES $(5.00 \mathrm{~g}, 20.21 \mathrm{mmol})$ and 4-(phenylazo)phenol (4.01 g, $20.21 \mathrm{mmol}$ ), the silane-coupling agent containing azobenzene structure (AzTES, 7.66 g, 85\% yield) was obtained as a red-colored solid: IR (KBr) 3290, 2970, 2880, 2250, 1700,1530 and $1090 \mathrm{~cm}^{-1} ;{ }^{1} \mathrm{H}$ NMR $\left(\mathrm{CDCl}_{3}\right) \delta 0.67(\mathrm{t}, 2 \mathrm{H}, J=8.0 \mathrm{~Hz}, \mathrm{Si}-$ $\left.\mathrm{CH}_{2}-\right), 1.22\left(\mathrm{t}, 9 \mathrm{H}, J=6.9 \mathrm{~Hz}, \mathrm{Si}-\mathrm{O}-\mathrm{CH}_{2}-\mathrm{CH}_{3}\right), 1.67\left(\mathrm{~m}, 2 \mathrm{H}, \mathrm{Si}-\mathrm{CH}_{2}-\mathrm{CH}_{2}-\right)$, $3 . \overline{2} 6\left(\mathrm{~m}, 2 \mathrm{H},-\mathrm{NH}-\mathrm{CH}_{2}-\right), 3.83\left(\mathrm{q}, 6 \mathrm{H}, J=7 . \overline{1} \mathrm{~Hz},-\mathrm{O}-\mathrm{CH}_{2}-\mathrm{CH}_{3}\right), 7.23(\mathrm{~m}, 2 \mathrm{H}$, $\left.-\mathrm{C}_{6} \mathrm{H}_{4^{-}}\right), 7.46\left(\mathrm{~m}, 3 \overline{\mathrm{H}}, \mathrm{C}_{6} \mathrm{H}_{5^{-}}\right)$and $7.89\left(\mathrm{~m}, 4 \mathrm{H}, \mathrm{C}_{6} \mathrm{H}_{5^{-}},-\mathrm{C}_{6} \mathrm{H}_{4}-\right) ;{ }^{13} \mathrm{C} \mathrm{NMR}$ $\left(\mathrm{CDCl}_{3}\right) \delta 7.6\left(\mathrm{Si}-\mathrm{CH}_{2}-\right), 18.2\left(\mathrm{Si}-\mathrm{O}-\mathrm{CH}_{2}-\mathrm{CH}_{3}\right), 23.0\left(\mathrm{Si}-\overline{\mathrm{CH}}_{2}-\mathrm{CH}_{2}-\right), 43.5$

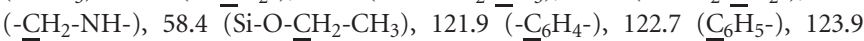
$\left(-\overline{\mathrm{C}}_{6} \mathrm{H}_{4^{-}}\right), 128.2\left(\underline{\mathrm{C}}_{6} \mathrm{H}_{5^{-}}\right), 1 \overline{28} .9\left(\mathrm{C}_{6} \mathrm{H}_{5^{-}}\right), 130.8\left(\overline{\mathrm{C}}_{6} \mathrm{H}_{5^{-}}\right), 149.6\left(-\overline{\mathrm{N}}=\mathrm{N}-\underline{\mathrm{C}}_{6} \mathrm{H}_{4^{-}}\right)$, $152.4\left(-\mathrm{N}=\mathrm{N}-\underline{\mathrm{C}}_{6} \mathrm{H}_{5}\right), 153.2\left(-\mathrm{O}_{-} \underline{C}_{6} \mathrm{H}_{4^{-}}\right)$and $154.0(-\mathrm{NH}-(\underline{\mathrm{C}}=\mathrm{O}) \mathrm{O}-)$.
Synthesis of polysilsesquioxane from silane-coupling agents by condensation

Typical procedure for condensation. A solution of the silane-coupling agent (TeTES, $1.00 \mathrm{~g}, 2.27 \mathrm{mmol})$ and $\mathrm{Et}_{3} \mathrm{~N}(0.01 \mathrm{~g}, 0.11 \mathrm{mmol})$ in acetone $(4 \mathrm{ml})$ and water $(1 \mathrm{ml})$ was refluxed for $24 \mathrm{~h}$. The resulting solution was concentrated using a rotary evaporator under reduced pressure and then an excess amount of ${ }^{n}$ hexane was added to the residual oil. The insoluble viscous oil was washed several times with nhexane by decantation and dried at an ambient temperature for $24 \mathrm{~h}$ in a vacuum oven under reduced pressure $(<5 \mathrm{~mm} \mathrm{Hg})$ to obtain a wax form of PSQ (TePSQ) $(0.37 \mathrm{~g}, 70 \%$ yield based on the ethylene glycol unit). The contents of the group were calculated from the corresponding peak areas observed in the ${ }^{1} \mathrm{H}$ NMR spectrum in which hexamethyldisiloxane was used as an internal standard: IR (neat) 3330, 2930, 1700, 1540 and $1120 \mathrm{~cm}^{-1} ;{ }^{1} \mathrm{H}$ NMR $\left(\mathrm{CDCl}_{3}\right) \delta 0.56\left(\mathrm{br}, \mathrm{Si}-\mathrm{CH}_{2}-\right), 1.51$ (br, Si- $\left.\mathrm{CH}_{2}-\mathrm{CH}_{2}{ }^{-}\right)$, 3.07 (br, $-\mathrm{CH}_{2}-\mathrm{NH}$ ), 3.54 (br, $-\mathrm{CH}_{2}-\mathrm{CH}_{2}-\mathrm{OH}$ ), 3.65 (br m, - $\mathrm{O}-\mathrm{CH}_{2}-\mathrm{CH}_{2}-\mathrm{O}-$ ) and $4.14\left(\mathrm{br},-(\mathrm{C}=\mathrm{O})-\mathrm{O}-\mathrm{CH}_{2}-\right) ;{ }^{13} \mathrm{C} \overline{\mathrm{NMR}}\left(\mathrm{CDCl}_{3}\right) \delta 7.4\left(\mathrm{Si}_{-} \mathrm{CH}_{2-}\right), 23.1(\mathrm{Si}-$ $\left.\mathrm{CH}_{2}-\mathrm{CH}_{2}-\right), 43.3\left(-\mathrm{NH}-\mathrm{CH}_{2}^{-}\right), 61.4\left(-\mathrm{CH}_{2}-\mathrm{CH}_{2}-\mathrm{OH}\right), 63.6\left(-(\overline{\mathrm{C}}=\mathrm{O})-\mathrm{O}-\mathrm{CH}_{2}-\right.$ ), $69 . \overline{4}\left(-(\mathrm{C}=\mathrm{O})-\mathrm{O}-\mathrm{CH}_{2}-\mathrm{CH}_{2}-\right), 70.3\left(-\mathrm{O}-\mathrm{CH}_{2}-\mathrm{CH}_{2}-\mathrm{O}-\right), 72.4\left(-\mathrm{CH}_{2}-\overline{\mathrm{C}} \mathrm{H}_{2}-\right.$ $\mathrm{OH})$ and $156.6(-(\mathrm{C}=\mathrm{O})-\overline{\mathrm{O}}-) ; M_{\mathrm{n}}=6400, \bar{M}_{\mathrm{w}} / \bar{M}_{\mathrm{n}}=1.03$.

Analogously, TeMPSQ was obtained in a $67 \%$ yield from the condensation of TeMTES

Co-condensation. A solution of TeMTES $(1.00 \mathrm{~g}, 2.19 \mathrm{mmol})$ with AzTES $(0.25 \mathrm{~g}, 0.55 \mathrm{mmol})$ and $\mathrm{Et}_{3} \mathrm{~N}(0.01 \mathrm{~g}, 0.11 \mathrm{mmol})$ in acetone $(4 \mathrm{ml})$ and water $(1 \mathrm{ml})$ was refluxed for $24 \mathrm{~h}$. The resulting solution was treated similarly to those mentioned in the preparation of TePSQ. The PSQ containing both the units of TeMTES and AzTES (TeMAzPSQ4) was obtained as a wax $(0.85 \mathrm{~g}$, 99\% yield based on the ethylene glycol unit, 99\% yield based on the azobenzene group): IR (neat) 3330, 2930, 2880, 1700, 1540 and $1110 \mathrm{~cm}^{-1}$; ${ }^{1} \mathrm{H}$ NMR $\left(\mathrm{CDCl}_{3}\right) \delta 0.59$ (br, Si- $\left.\mathrm{CH}_{2-}\right), 1.55$ (br, Si- $\left.\mathrm{CH}_{2}-\mathrm{CH}_{2}-\right), 3.08(\mathrm{br}$, $\mathrm{CH}_{2}-\mathrm{NH}$ ), 3.31 (br, $-\mathrm{O}-\mathrm{CH}_{3}$ ), 3.47-3.58 (br m, - $-\mathrm{CH}_{2}-\mathrm{CH}_{2}-\mathrm{O}-$ ), 4.13 (br, $\left.(\overline{\mathrm{C}}=\mathrm{O})-\mathrm{O}-\mathrm{CH}_{2} 2^{-}\right), 5.43$ (br, $\left.-\mathrm{NH}-\right), 7.21$ (br m, $\left.-\mathrm{C}_{6} \mathrm{H}_{4}-\right), 7.42$ (br m, $\mathrm{C}_{6} \mathrm{H}_{5^{-}}$) and 7.85 (br $\left.\overline{\mathrm{m}}, \mathrm{C}_{6} \mathrm{H}_{5^{-}},-\mathrm{C}_{6} \mathrm{H}_{4^{-}}\right) ;{ }^{13} \mathrm{C}$ NMR $\left(\mathrm{CDCl}_{3}\right) \bar{\delta} 9.5\left(\mathrm{Si}_{-}-\mathrm{CH}_{2^{-}}\right), 23.2(\mathrm{Si}-$ $\left.\mathrm{CH}_{2}-\mathrm{CH}_{2-}\right), 43.2\left(-\mathrm{NH}_{-} \mathrm{CH}_{2-}\right), 58.9\left(-\mathrm{O}-\mathrm{CH}_{3}\right), 63.7$ (-(C=O)-O-CH $\left.2^{-}\right), 69.5$ $\left(-(\mathrm{C}=\mathrm{O})-\mathrm{O}-\mathrm{CH}_{2}-\mathrm{CH}_{2}-\right), 70.3\left(-\mathrm{O}-\mathrm{CH}_{2}-{ }_{-} \mathrm{CH}_{2}-\mathrm{O}-\right), 71.8\left(-\mathrm{CH}_{2}-\mathrm{O}-\overline{\mathrm{CH}}_{3}\right), 122.0$ $\left(-\mathrm{C}_{6} \mathrm{H}_{4^{-}}\right), 122.7\left(\mathrm{C}_{6} \mathrm{H}_{5^{-}}\right), 123.8\left(-\mathrm{C}_{6} \overline{\mathrm{H}}_{4^{-}}\right), \overline{1} 28.9\left(\mathrm{C}_{6} \mathrm{H}_{5^{-}}\right), \overline{13} 0.9\left(\mathrm{C}_{6} \mathrm{H}_{5^{-}}\right), 149.5$ $\left(-\overline{\mathrm{N}}=\mathrm{N}-\mathrm{C}_{6} \mathrm{H}_{4^{-}}\right), \quad 152.7 \quad\left(\mathrm{C}_{6} \mathrm{H}_{5}-\overline{\mathrm{N}}=\mathrm{N}-\right), \quad 153.5 \quad\left(-\mathrm{O}-\mathrm{C}_{6} \mathrm{H}_{4^{-}}\right) \quad$ and 156.7 (-( $\mathrm{C}=\mathrm{O})-\mathrm{O}-)$.

Analogously, the co-condensations using TeTES or TeMTES with AzTES produced the PSQs containing both silyl units. The results are shown in Table 1.

\section{Measurement of transmittance (\%T)}

A $1.0 \mathrm{wt} \%$ solution of the PSQ in distilled water, obtained from EYELA SA2100A (Tokyo Rikakikai Co, Tokyo, Japan), was used for the measurement of transmittance $(\% \mathrm{~T})$ on a Shimadzu UV-1650 spectrophotometer (Shimadzu Co, Kyoto, Japan) equipped with a Peltier-type S-1700 thermostatic cell holder

Table 1 Preparation of PSQ from a silane-coupling agent ${ }^{a}$

\begin{tabular}{|c|c|c|c|c|c|c|c|}
\hline $\begin{array}{l}\text { Silane-coupling } \\
\text { agent of ethylene } \\
\text { glycols }\end{array}$ & $\begin{array}{l}\text { Co-silane- } \\
\text { coupling } \\
\text { agents }\end{array}$ & $\begin{array}{c}\text { Feed mole } \\
\text { ratio of TeTES } \\
\text { or TeMTES/ } \\
\text { co-agent }\end{array}$ & $P S Q$ & $\begin{array}{c}\text { Molar unit } \\
\text { ratio of ethylene } \\
\text { glycol/co-agent }\end{array}$ & $\begin{array}{l}\text { Content of ethylene } \\
\text { glycol unit, }{ }^{\text {b }} \\
\text { mmol equivg }{ }^{-1} \\
\text { (yield, \%) }\end{array}$ & $\begin{array}{l}\text { Content of } \\
\text { co-agent unit, } \\
\text { mmol equivg } \\
\text { (yield, \%) }\end{array}$ & $M_{n}\left(M_{w} / M_{n}\right)^{c}$ \\
\hline TeTES & - & - & TePSQ & - & $4.35(70)$ & - & 6400 (1.05) \\
\hline TeMTES & - & - & TeMPSQ & - & $4.53(57)$ & - & $5100(1.08)$ \\
\hline TeTES & AzTES & 8 & TeAzPSQ8 & 9.0 & $3.15(95)$ & 0.35 (99) & $7900(1.82)$ \\
\hline TeMTES & AzTES & 4 & TeMAzPSQ4 & 4.1 & 2.80 (99) & 0.68 (99) & $4300(1.13)$ \\
\hline TeMTES & AzTES & 8 & TeMAzPSQ8 & 8.3 & $2.90(98)$ & $0.35(94)$ & $4300(1.15)$ \\
\hline TeMTES & AzTES & 15 & TeMAzPSQ15 & 15.5 & 3.10 (99) & $0.20(94)$ & $4500(1.13)$ \\
\hline
\end{tabular}

Abbreviation: PSQ, Polysilsesquioxane.

aThe condensation was conducted with a catalytic amount of triethylamine in the mixed solvents of acetone and water under reflux for $24 \mathrm{~h}$.

${ }^{\mathrm{b}}$ The estimation was based on ${ }^{1} \mathrm{H}$ NMR spectral data (see Experimental procedure).

'Estimated relative to poly(methyl methacrylate) standards. 
During the measurements, the changes of $\% \mathrm{~T}$ were observed from a visible source at $800 \mathrm{~nm}$ through a $1-\mathrm{cm}$ quartz sample cell at a rate of $1{ }^{\circ} \mathrm{C} \mathrm{min}{ }^{-1}$ during heating and cooling scans. The measurements were repeated at least three times for each sample until there was good agreement in the observed curves.

Photochemical isomerization was performed by irradiation using a $300 \mathrm{~W}$ xenon lamp (Asahi Spectra Co, Max-301, Tokyo, Japan) equipped with optical filters of $350 \mathrm{~nm}$ and $440 \mathrm{~nm}$ for cis and trans isomerizations of the 4phenylazobenzene group, respectively. The changes in absorbance after photoirradiation were measured using $0.01 \mathrm{wt} \%$ aqueous solution of the PSQs.

\section{RESULTS AND DISCUSSION}

Preparation and condensation of silane-coupling agent

The synthetic route to the PSQs from the corresponding silanecoupling agents is shown in Scheme 1. Preparation of the silanecoupling agents was performed using the simple addition reaction of the tetraethylene glycol derivatives to ICTES with a catalytic amount of $\mathrm{Et}_{3} \mathrm{~N}$ at $50^{\circ} \mathrm{C}$ in which the tetraethylene glycol compounds were introduced through a urethane bond. The use of a half molar amount of ICTES to tetraethylene glycol led to the formation of the agent containing the end-hydroxyl ethylene glycol chain. The corresponding agent was isolated by column chromatography in an $82 \%$ yield. The reaction of ICTES with 4-hydroxyphenylazobenzene was performed for the formation of the silane-coupling agents containing the azobenzene group, in which AzTES was obtained in an 85\% yield.

The transformation of the silane-coupling agents to PSQs was carried out with a catalytic amount of $\mathrm{Et}_{3} \mathrm{~N}$ in the mixed solvents of acetone and water under reflux. When methanesulfonic acid was used as a catalyst for the condensation of TeTES, a cross-linked product that was insoluble in any solvent was formed. By the condensation of TeTES under the basic conditions, TePSQ, which had a hydroxyl group at the end of the ethylene glycol chain, was obtained in a $70 \%$ yield as a viscous oil. Analogously, the PSQ containing methyl ether in the tetraethylene glycol chain, TeMPSQ, was prepared in a $67 \%$ yield. In these condensations, the yields of the products and the contents of the silyl units were estimated by ${ }^{1} \mathrm{H}$ NMR spectral data. TePSQ and TeMPSQ were soluble in versatile organic solvents and water. To provide the thermoresponsive property to TePSQ and TeMPSQ, the presence of a hydrophobic component was required in addition to the tetraethylene glycol chains. Consequently, the co-condensation of the silane-coupling agents was adopted in this work. In this method, TeTES or TeMTES were combined with AzTES as the hydrophobic component, which was expected to provide the photoresponsive geometric isomerization. The results of the co-condensation are shown in Table 1. On the basis of the content of the groups, the yields were greater than $60 \%$. For the preparations of TeAzPSQ8 and TeMAzPSQs, the respective units were incorporated almost quantitatively.

The formation of the silane-coupling agents and PSQs were confirmed by the spectral data. For an example of the PSQs, the ${ }^{1} \mathrm{H}$ NMR spectrum of TeMAzPSQ4, obtained by the co-condensation of TeMTES and AzTES, is provided in Figure 1. The spectrum displays the presence of both units of the silane-coupling agents. The signals observed in the spectra of TeMTES and AzTES were also detected, but the signals due to the ethoxy group of the silanecoupling agents disappeared in the spectrum of TeMAzPSQ4. In the spectrum, the signals observed at 0.6, 1.5 and 3 p.p.m. demonstrate the presence of propyl groups bonded to Si. The signals of methylene protons in the tetraethylene glycol chain appeared in the region from 3.64 to 3.83 p.p.m. The signal of the end-methyl protons of tetraethylene glycol chain appeared at 3.31 p.p.m. The methylene protons of the urethane bond are observed at 4.18 p.p.m. The

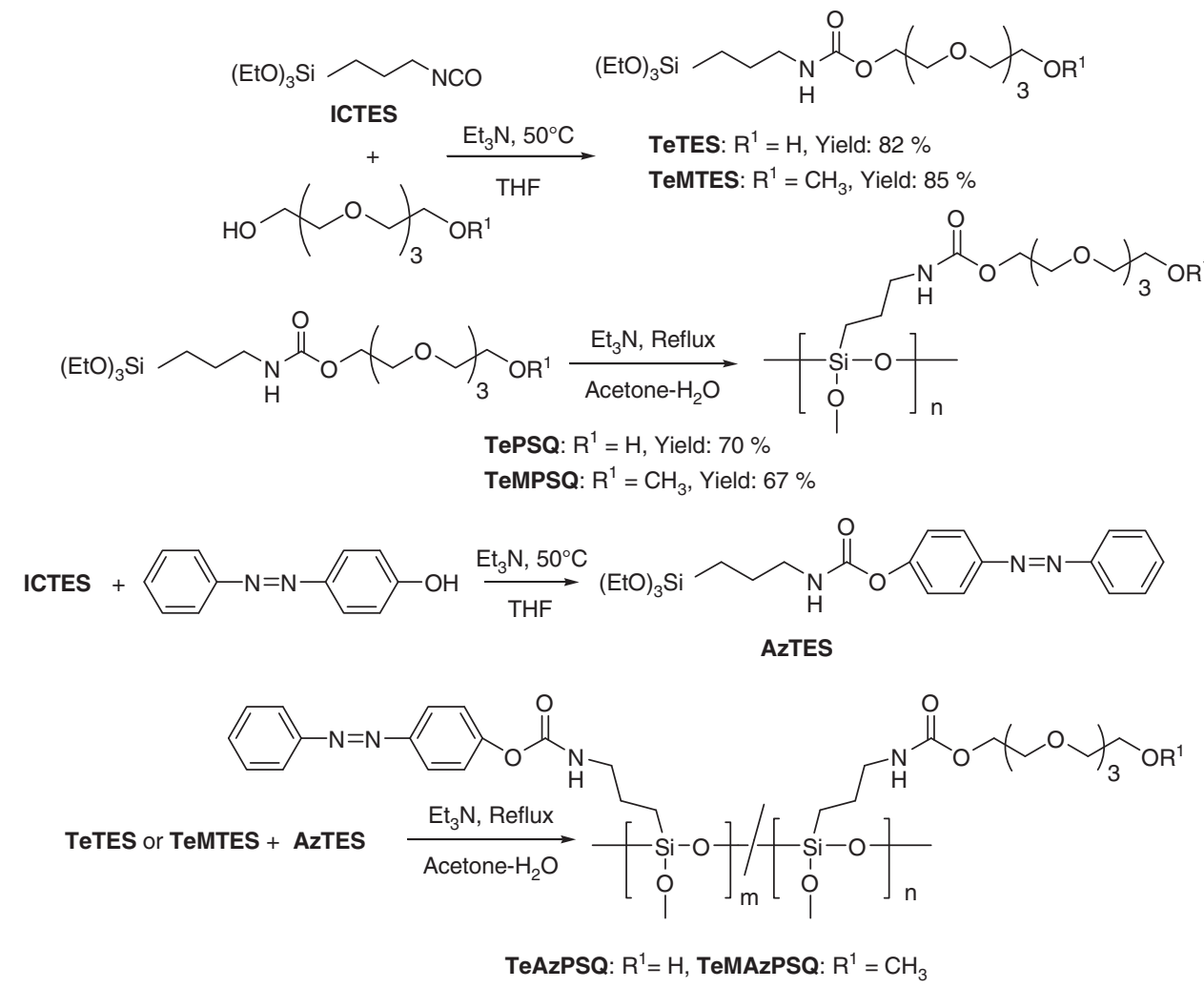

Scheme 1 Synthetic route to PSQ 


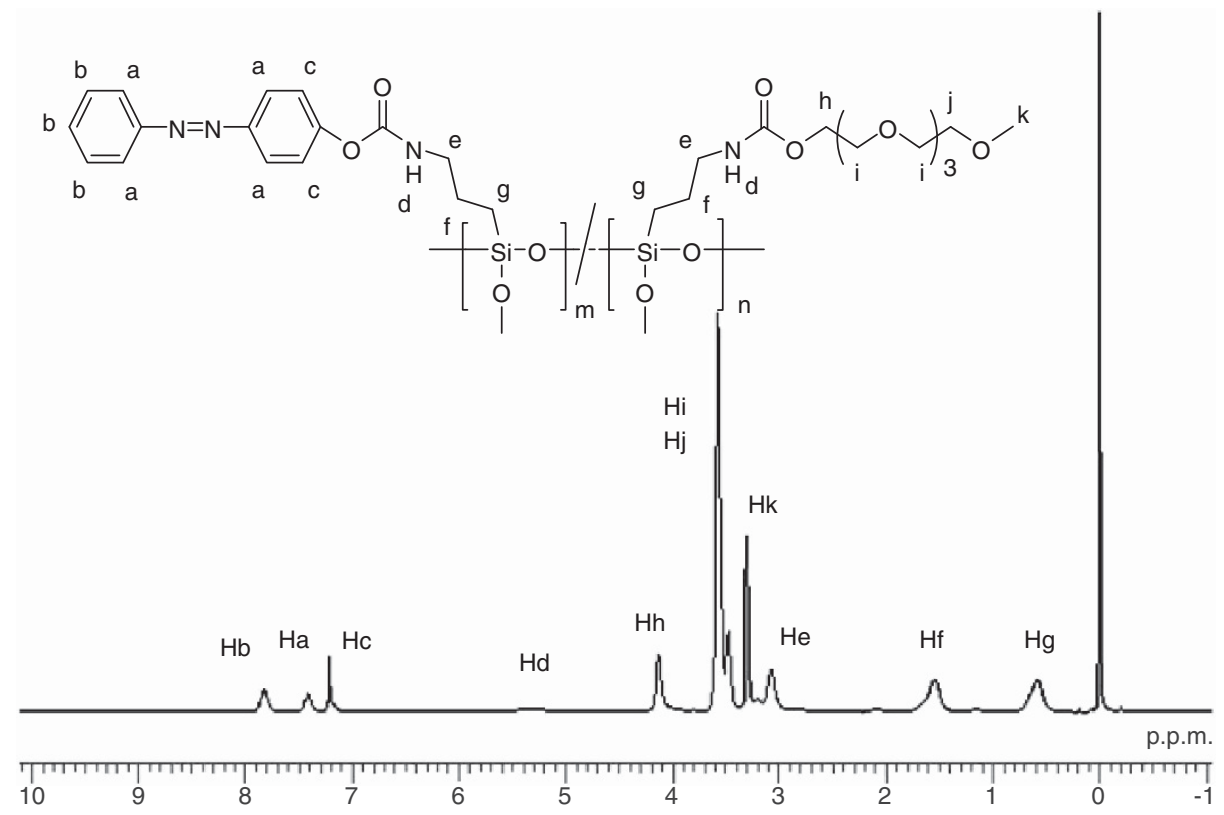

Figure 1 The ${ }^{1} \mathrm{H}$ NMR spectrum of TeMAzPSQ4. A full color version of this figure is available at Polymer Journal online.

presence of the 4-phenylazobenzoate structure is observed from the signals of the benzene ring protons at 7.50, 7.94 and 8.20 p.p.m. The areas of those specific signals were utilized for the calculation of the contents of the units.

The IR and ${ }^{13} \mathrm{C}$ NMR also support the formation of the desired PSQs. In the IR spectra, the absorption $\sim 1100 \mathrm{~cm}^{-1}$ is assigned to ether and siloxy bonds. The presence of urethane bonds is demonstrated by the strong absorption, which appeared at $1700 \mathrm{~cm}^{-1}$ owing to the stretching vibration of the carbonyl group. In the ${ }^{13} \mathrm{C} \mathrm{NMR}$ spectra, the carbon signals of the ethylene glycol group are observed from 60 to 70 p.p.m. The signals that appeared at 157 p.p.m. are assigned to the carbonyl carbon of the urethane bond. The specific signal owing to the carbon bonded to Si is at 7 p.p.m. Those signals were commonly observed in all the spectra of the silane-coupling agents and PSQs. In the spectra of the TeMTES and the PSQs obtained from this coupling agent, a signal at 59 p.p.m. was detected that is due to the carbon of the end-methyl group. In the derivatives containing the azobenzene structure, the signals assigned to the carbons of the benzene ring at 125 p.p.m. However, the exact structures of the polysiloxane backbone have not been determined in this work. Nevertheless, the structure is speculated to consist of an incomplete ladder and cage structure, not a randomly cross-linked one. For example, the ${ }^{29} \mathrm{Si}$ NMR spectrum of TeMAzPSQ4 is shown in Figure 2. The signals corresponding to both the $\mathrm{T}^{3}$ and $\mathrm{T}^{2}$ structures are clearly observed at -77.5 p.p.m. and -69.0 p.p.m., respectively. The ratio of the peak areas of $\mathrm{T}^{3} / \mathrm{T}^{2}$ is $1: 6$. The presence of both the signals suggests that the obtained PSQ does not primarily consist of the cage structure known as a polyhedral oligomeric silsesquioxane. The analogous analytical result was obtained in our previous report concerning the preparation of phenyl-substituted PSQ. ${ }^{37}$

The $M_{\mathrm{n}}$ s of the obtained PSQs were estimated by gel permeation chromatography in which $\mathrm{N}, \mathrm{N}$-dimethylformamide and poly(methyl methacrylate) standards were employed as the eluent and the standard, respectively. In those estimations, the $M_{\mathrm{n}}$ of TePSQ was indicated to be 6400 , and the $M_{\mathrm{n}}$ of TeMPSQ, which has a

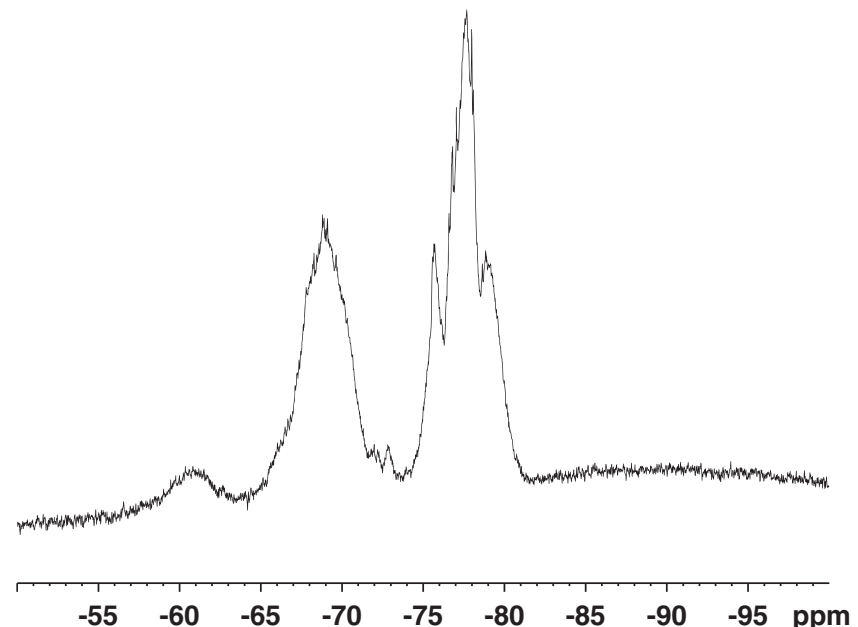

Figure 2 The ${ }^{29} \mathrm{Si}$ NMR spectrum of TeMAzPSQ4. A full color version of this figure is available at Polymer Journal online.

methyl-end group, was 5100. The polydispersities of TePSQ and TeMPSQ were 1.03 and 1.08 , respectively. The $M_{\mathrm{n}} \mathrm{s}$ of the PSQs obtained by co-condensation were estimated between 4300 and 7900 . In all the chromatograms of the obtained PSQs, a unimodal peak was observed. This finding suggested that the expected co-condensation progressed.

\section{Thermally reversible phase separation}

Thermoresponsive aggregation behavior was evaluated by the turbidity measured as $\% \mathrm{~T}$ at $800 \mathrm{~nm}$ on heating and cooling. TePSQ and TeMPSQ are soluble in water, but did not exhibit thermoresponsive hydrophobic aggregation below $70^{\circ} \mathrm{C}$. This behavior demonstrated that the PSQs had amphiphilic properties owing to the presence of the tetraethylene glycol chains. Consequently, the hydrophobic azobenzene component in the other silyl unit was introduced to provide reversible aggregation behavior. The PSQ containing the 
hydrophobic azobenzene group at the end of the ethylene glycol chain was also prepared in the preliminary experiment. However, this type of PSQ was too hydrophobic to dissolve in water even when the molar unit ratio of the end-hydroxyl group to the end-azobenzene group was above 20. Therefore, the co-condensated PSQs, in which the tetraethylene glycol chain and the azobenzene group were located in each of the silyl units, were prepared in this work.

The thermoresponsive behaviors of TeAzPSQ and TeMAzPSQs, are depicted in Figure 3, and the behaviors on cooling are excluded for easy viewing. TeAzPSQ8, which was obtained by the co-condensation of TeTES and AzTES, showed $40{ }^{\circ} \mathrm{C}$ for LCST. The LCST of TeMAzPSQ8, which contained a similar unit ratio for the end methylated ethylene glycol chain to the azobenzene group (for example, 8:1), was $35^{\circ} \mathrm{C}$. The difference in LCST indicated that the end-methyl group of the ethylene glycol chain in TeMAzPSQ8 favorably affected the hydrophobic aggregation behavior. The LCSTs of TeMAzPSQs decreased with an increase in the content of the azobenzene group. For example, a decrease in LCST from $36{ }^{\circ} \mathrm{C}$ of TeMAzPSQ15 to $32^{\circ} \mathrm{C}$ of TeMAzPSQ4 was observed. The estimated unit ratio of the ethylene glycol chain to the azobenzene group in TeMAzPSQ15 was 15.5 and was 4.1 for TeMAzPSQ4. These results suggest that the effect of the hydrophobic group at the end of the ethylene glycol chain on the LCST is larger than for the group introduced into the other silyl unit.

The methacrylate polymer containing the (4-phenylazo)phenoxy groups in the side chains displays an increase in LCST after ultraviolet irradiation at $346 \mathrm{~nm}$ in which the geometrical isomerization of the azobenzene group from a trans to a cis conformation occurs. ${ }^{38}$ When the configuration is returned to a trans-isomer by photoirradiation at $420 \mathrm{~nm}$, a depression in the LCST of $3{ }^{\circ} \mathrm{C}$ is observed. ${ }^{39}$ These aggregation behaviors can be explained by an increase in polarity of the cis-isomer, which should become more hydrophilic. In contrast to this change in LCST based on polarity, a depression of LCST is observed in the work reported by Marie and Tribet ${ }^{40}$ and is caused by the formation of the cis-isomer. Furthermore, in our previous study, a depression in LCST was found in which sodium 4-phenylazobenzoate was introduced into the PSQ through the coordination to the 15crown-five-ether ring. ${ }^{12}$ Consequently, the behaviors examined here are anticipated to present additional data regarding the geometric change effects of the phenylazobenzoate group on the aggregation temperature.

The photoresponsive property of TeMAzPSQ15 is shown in Figure 4. A portion of the $1 \mathrm{wt} \%$ aqueous solution of TeMAzPSQ15

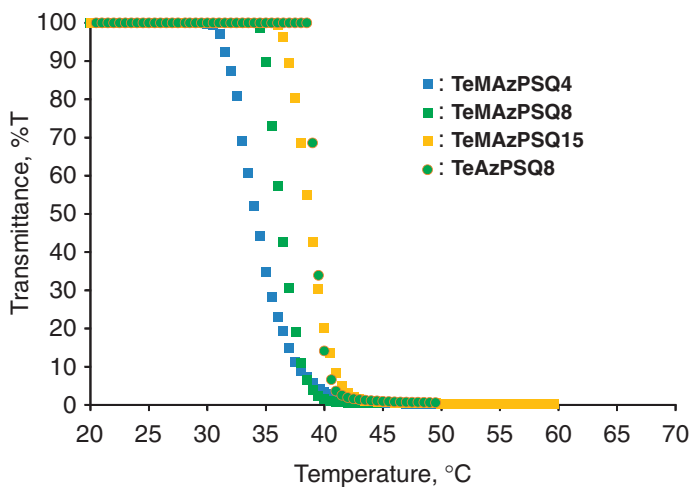

Figure 3 Temperature dependence of optical transmittance (\%T) at $800 \mathrm{~nm}$ for 1 wt $\%$ aqueous solution of TeAzPSQ8 and TeMAzPSQs on heating $\left(1^{\circ} \mathrm{Cmin}^{-1}\right)$. was diluted in water to a final concentration of $0.01 \%$ for the UV absorption. The spectrum indicated the presence of the trans-form of the phenylazobenzene group. Next, the diluted solution was photoirradiated at $350 \mathrm{~nm}$ for $2 \mathrm{~h}$. In the UV spectrum of the resulting solution, the intensity of the absorbance at $\sim 330 \mathrm{~nm}$, which is due to the trans-azobenzene group, decreased. ${ }^{38}$ This observation indicates that the isomerization from the trans-form to the cis-form occurred. The aggregation behavior of the resulting solution was also measured. As shown in Figure 5, the obtained \% $\mathrm{T}$ curve indicated that the aggregation began at $31^{\circ} \mathrm{C}$. In comparison with the behavior before the photoirradiation of $350 \mathrm{~nm}$, the LCST decreased to $\sim 6^{\circ} \mathrm{C}$. Then, the solution was treated at $440 \mathrm{~nm}$ for $2 \mathrm{~h}$. After this treatment, the LCST also returned to the original value of $37^{\circ} \mathrm{C}$. In the UV spectrum of the diluted solution, the recovery of the trans-isomer of the azobenzene structure was detected. Thus, the change in LCST from 37 to $31^{\circ} \mathrm{C}$ by the photoirradiation of 350 and $440 \mathrm{~nm}$ was confirmed. In the independent experiment, no thermal isomerization was observed during the measurements in which the temperature was raised to $70{ }^{\circ} \mathrm{C}$. The analogous photoresponsive and thermoresponsive reversible behaviors were observed in the aqueous solutions of TePSQ and other TeMAzPSQs. In addition, the aggregation behaviors focused on the reversible photoresponsive property in which the temperature of the aqueous solution was maintained at $35^{\circ} \mathrm{C}$, as presented in Figure 6 . When the solution was irradiated with $350 \mathrm{~nm}$ light, an

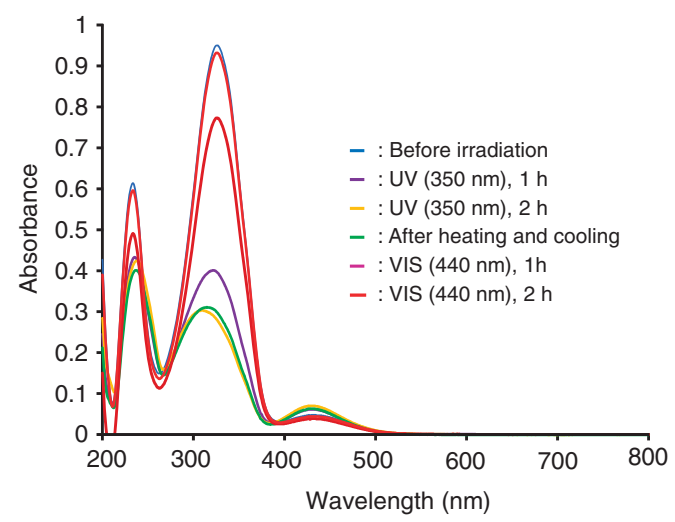

Figure 4 UV spectrum of 0.01 wt\% aqueous solution of TeMAzPSQ15 after photoirradiation at $350 \mathrm{~nm}$ for the cis-isomer and at $440 \mathrm{~nm}$ for the transisomer.

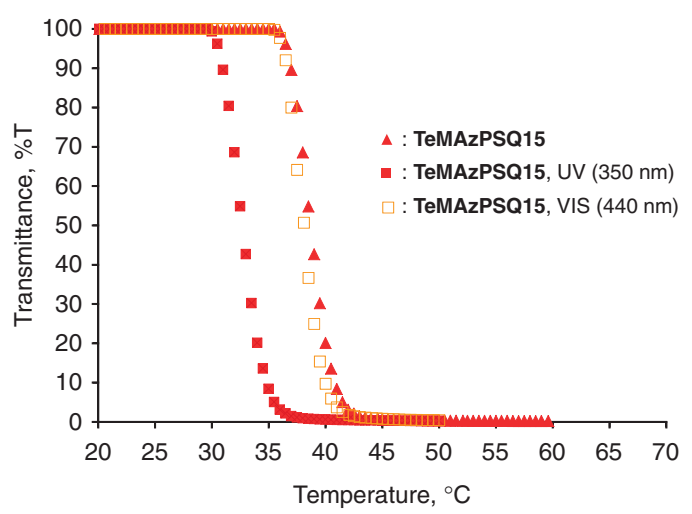

Figure 5 Temperature dependence of optical transmittance (\%T) at $800 \mathrm{~nm}$ for 1 wt $\%$ aqueous solution of TeMAzPSQ15 on heating $\left(1^{\circ} \mathrm{C} \mathrm{min}{ }^{-1}\right)$. 


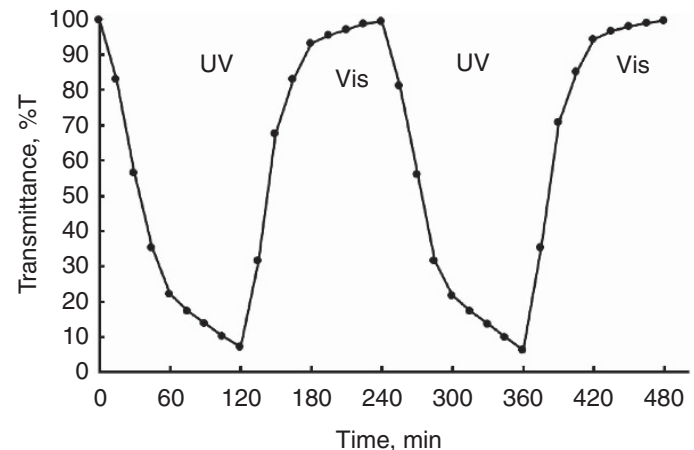

Figure 6 Optical transmittance (\%T) of 1 wt\% aqueous solution of TeMAzPSQ15 at $800 \mathrm{~nm}$ on photoirradiation at $350 \mathrm{~nm}$ and $440 \mathrm{~nm}$ at $35^{\circ} \mathrm{C}$.

insoluble component appeared. Irradiation of the solution with the visible light at $440 \mathrm{~nm}$ dissolved the insoluble component. The behaviors were again observed when the experiments were repeated. Specifically, the solubility of TeMAzPSQ15 in water was easily controlled by photoirradiations.

In support of our previous results, the results here indicate that the presence of the azobenzene group induces the photoresponsive and thermoresponsive properties and the cis-isomer of the azobenzene group leads to a lower LCST compared with the trans-isomer. The depression of the temperature, as in the case of the cis-form, may be explained by steric effects. The cis-form is thought to occupy a wider space than the trans-form around the polysiloxane backbone. This extends the hydrophobic groups, including the azobenzene structure, outward from the backbone. The presence of hydrophobic components near the outside should be favorable for the aggregation, which results in a depression in LCST. However, the conclusion requires more detailed experiments on the location and the situation of the phenylazobenzoate group on the PSQ backbone. At this stage, it is apparent that the photoisomerization of the introduced azobenzene structure provides mutually interacting photo- and thermoresponsive properties to the PSQ.

\section{CONCLUSIONS}

The introduction of tetraethylene glycol chains into PSQ through a urethane bond was utilized for the synthesis of new amphiphilic hybrid materials. The condensation of the silane-coupling agents for the preparation of the PSQs progressed efficiently under basic conditions without formation of any cross-linked by-products. The combination of the hydrophilic ethylene glycol silyl unit with another silyl unit that contains a hydrophobic component was effective for providing the controlled thermoresponsive property. The use of an azobenzene group as the hydrophobic component resulted in the photoresponsive function. By the introduction of the 4-phenylazobenzene structure, a change in LCST was observed according to the photoresponsive geometrical isomerization. The results indicated that the transformation of the azobenzene structure into a cis-form caused a depression in the aggregation temperature. The phenomenon presents fundamental information concerning the dual thermo- and photoresponsive properties in which the effect of geometric isomerization on LCST should not be simply explained by the polarity of the azobenzene structure.

Thus, the use of the silane-coupling agents, respectively, containing the ethylene glycol chain and the hydrophobic component is a convenient and practical synthesis method for multistimuli- responsive PSQ derivatives in aqueous solution. Furthermore, the easy introduction of oligo(ethylene glycol) building block chains into the silane-coupling agent should contribute to the preparation of various environmentally friendly PSQs.

1 Baney, R. H. \& Cao, X. In Silicon-Containing PolymersJohns, R. G., Ando, W. \& Chojnowski, J. Eds. (Kluwer, Dordrecht, 2000).

2 Brown, J. F. Jr, Vogt, L. H. Jr, Katchman, A., Eustance, J. W. Kaiser, K. M. \& Krantz, K. W. Double chain polymers of phenylsilsesquioxane. J. Am. Chem. Soc. 82, 6194-6195 (1960)

3 Roy, D. A. \& Shea, K. J. Bridged polysilsesquioxanes. highly porous hybrid organicinorganic materials. Chem. Rev. 95, 1431-1442 (1995).

4 Kondo, T., Yoshi, K., Horie, K. \& Itoh, M. Photoprove study of siloxane polymers. 3. Local free volume of polymethylsilsesquioxane proved by photoisomerization of azobenzene. Macromolecules 33, 3650-3658 (2000).

5 Gunji, T., lizuka, Y., Arimitsu, K. \& Abe, Y. Preparation and properties of alkoxy (methyl)silsesquioxanes as coating agents. J. Polym. Sci. A Polym. Chem. 42, 3676-3684 (2004)

6 Chauhan, B. P. S. \& Latif, U. Inorganic/ organic hybrid nanoreactors based on cyclic and cubic siloxane scaffolds. Macromolecules 38, 6231-6235 (2005).

7 Chang, C.-L. \& Ma, C.-C. M. Synthesis, characterization, and properties of novel ladderlike phosphorus-containing polysilsesquioxanes. J. Polym. Sci. Polym. Chem. 41, 1371-1379 (2003).

8 Heskins, M. \& Guillet, J. E. Solution properties of poly(N-isopropylacrylamide) J. Macromol. Sci. Chem. 2, 1441-1455 (1968).

9 Chen, G. H. \& Hoffman, A. S. Graft copolymers that exhibit temperature induced phase transitions over a wide range of pH. Nature 373, 49-52 (1995).

10 Meyer, S. \& Richtering, W. Influence of polymerization conditions on the structure of temperature-sensitive poly( $\mathrm{N}$-isopropylacrylamide) microgels. Macromolecules $\mathbf{3 8}$, 1517-1519 (2005)

11 Matsuoka, T., Yamamoto, S. \& Moriya, O. A new amphiphilic and thermoresponsive polysilsesquioxane having alkoxyethylamide group. Chem. Lett. 37, 772-773 (2008).

12 Matsuoka, T., Yamamoto, S., Moriya, O., Kashio, M. \& Sugizaki, T. Synthesis of thermoresponsive polysilsesquioxane with methoxyethylamide group and crown ether Polym. J. 42, 313-318 (2010).

13 Minami, F., Yamamoto, S., Miyasaka, Y. \& Moriya, O. Synthesis of thermo- and pH responsive polysilsesquioxane with carboxylic acid group. Polymer 52, 4744-4752 (2011).

14 Aoshima, S. \& Sugihara, S. Syntheses of stimuli-responsive block copolymers of vinyl ethers with side oxyethylene groups by living cationic polymerization and their thermosensitive physical gelation. J. Polym. Sci. A Polym. Chem. 38, 3962-3965 (2000).

15 Sugihara, S., Kanaoka, S. \& Aoshima, S. Double thermosensitive diblock copolymers of vinyl ethers with pendant oxyethylene groups: Unique physical gelation. Macromolecules 38, 1919-1927 (2005).

16 Lin, H.-H. \& Cheng, Y.-L. In-Situ thermoreversible gelation of block and star copolymers of poly(ethylene glycol) and poly( $\mathrm{N}$-isopropylacrylamide) of varying architectures. Macromolecules 34, 3710-3715 (2001)

17 Han, S., Hagiwara, M. \& Ishizone, T. Synthesis of thermally sensitive water-soluble polymethacrylate by living anionic polymerization of oligo(ethylene glycol) methyl ether methacrylates. Maclomolecules 36, 8312-8319 (2003).

18 Gil, E. S. \& Hudson, S. M. Stimuli-responsive polymers abd their bioconjugates. Prog. Polym. Sci. 29, 1173-1222 (2004).

19 Hua, F., Jiang, X. \& Zhao, B. Temperature-induced self-association of doubly thermosensitive Diblock copolymers with pendant metoxytris(oxyethylene) groups in dilute aqueous solutions. Macromolecules 39, 3476-3479 (2006).

20 Yamamoto, S., Pietrasik, J. \& Matyjaszewski, K. ATRP synthesis of thermally responsive molecular brushes from oligo(ethylene oxide) methacrylates. Macromolecules 40, 9348-9353 (2007).

21 Thommas, J. D., Fussell, G. Sarkar, S., Lowman, A. M. \& Marcolongo, M. Synthesis and recovery characteristics of branched and grafted PNIPAAm-PEG hydrogels for the development of an injectable load-bearing nucleus pulposus replacement. Acta Biomater. 6, 1319-1328 (2010).

22 Nagasaki, Y. Construction of a densely poly(ethylene glycol)-chain-tethered surface and its performance. Polym. J. 43, 949-958 (2011).

23 Weber, C., Hoogenboom, R. \& Schubert, U. S. Temperature responsive bio-compatible polymers based on poly(ethylene oxide) and poly(2-oxazoline)s. Prog. Polym. Sci. 37, 686-714 (2012)

24 Zeng, Y. \& Pitt, W. G. Poly(ethylene oxide)-b-poly(N-isopropylacrylamide) nanoparticles with crosslinked cores as drug carriers. J. Biomater. Sci. Polym. Ed. 16, 371-380 (2005)

25 Garćia-Garćia, J. M., Liras, M., Quijada-Garrido, I., Gallardo, A. \& París, R. Swelling control in thermo-responsive hydrogels based on 2-(2-methoxyethoxy)ethyl methacrylate by crosslinking and copolymerization with $\mathrm{N}$-isopropylacrylamide. Polym. J. 43, 887-892 (2011)

26 Lutz, J.-F. \& Hoth, A. Preparation of ideal PEG anlogues with a tunable thermosensitivity by controlled radical copolymerization of 2-(2-methoxyethoxy)ethy methacrylate and oligo(ethylene glycol) mathacrylate. Macromolecules 39, 893-896 (2006) 
27 Fissi, A. \& Pierori, O. Photoresponsive polypeptides. Photomodulation of the macromolecular structure in azo-modified poly(L-glutamic acid). Macromolecules 22, 1115-1120 (1989).

28 Beattie, M. S., Jackson, C. \& Jaycox, G. D. Azobenzene modified poly(aryl ether ketone amide)s. 2. Photo- and thermo-responsive behavior in dilute solution. Polymer 39, 2597-2605 (1998).

29 Yoshida, T., Kanaoka, S. \& Aoshima, S. Photo-responsive copolymers with azobenzene side groups synthesized by living cationic polymerization: efficient amplification of photosensitivity in aqueous photo-switching system. J. Polym. Sci. A Polym. Chem. 43 , 5337-5342 (2006).

30 Akiyama, H. \& Tamaoki, N. Synthesis and photoinduced phase transitions of poly(Nisoproplacrylamide) derivative functionalized with terminal azobenzene units. Macromolecules 40, 5129-5132 (2007).

31 Ishii, N., Mamiya, J., Ikeda, T. \& Winnik, F. M. Solvent induced amplification of the photoresponsive properties of a,w-di[4-cyanophenyl-4'-(6-hexyloxy)-azobenzene]-poly (N-isopropylacrylamide) in aqueous media. Chem. Commun. 47, 1267-1269 (2011).

32 Tang, X. Liang, X., Gao, L., Fan, X. \& Zhou, Q. Water-soluble triply-responsive homopolymers of $\mathrm{N}, \mathrm{N}$-dimethylaminoethyl methacrylate with a terminal azobenzene moiety. J. Polym. Sci. A Polym. Chem. 48, 2564-2570 (2010).

33 Jochum, F. D., Boorg, L. Z., Roth, P. J. \& Theato, P. Thermo- and light-responsive polymers containing photoswitcable azobenzene end group. Macromolecules 42 , 7854-7862 (2010).
34 Liu, J., Chen, G., Guo, M. \& Jiang, M. Dual stimuli-responsive supramolecular hydrogel based on hybrid inclusion complex (HIC). Macromolecules 43, 8086-8093 (2010).

$35 \mathrm{Hu}$, J. \& Liu, S. Responsive polymers for detection and sensing applications: current status and future development. Macromolecules 43, 8315-8330 (2010).

36 Dirani, A., laloyaux, X., Fernandes, A. E., Mathy, B., Schicke, O., Riant, O., Nysten, B. \& Jonas, A. M. Reversible photomodulation of the swelling of poly(oligo(ethylene glycol) methacrylate) thermoresponsive polymer brushes. Macromolecules 45, 9400-9408 (2012).

37 Matsubara, Y., Konishi, W., Sugizaki, T. \& Moriya, O. Synthesis of poly(phenylsilsesquioxane) having organostannyl groups. J. Polym. Sci. A Polym. Chem. 39, 2125-2133 (2001).

38 Uchida, E. \& Kawatsuki, N. Influence of wavelength of light on photochemical orientation of azobenzene-containing polymethacrylate film. Polym. J. 38, 724-731 (2006).

39 Ravi, P., Sin, S. L., Gan, L. H., Gan, Y. Y., Tam, K. C., Xia, X. L. \& Hu, X. New water soluble azobenzene-containing diblock copolymers: synthesis and aggregation behavior. Polymer 46, 137-146 (2003).

40 Marie, E. \& Tribet, C. Reverse variation of cloud points of light-responsive assemblies of azobenzene-modified amphiphilic polymers. Chem. Lett. 41, 1093-1095 (2012). 